\title{
Comparison of Shaping Ability of Different Single-File Systems Using Microcomputed Tomography
}

\author{
${ }^{1}$ Department of Periodontics, Dental College of Georgia, \\ Augusta University, Augusta, Georgia, United States \\ ${ }^{2}$ Department of Endodontics, Faculty of Dentistry, \\ Ain Shams University, Cairo, Egypt \\ ${ }^{3}$ Department of Endodontics, Faculty of Dentistry, \\ The British University in Egypt, Cairo, Egypt \\ ${ }^{4}$ Department of Endodontics, Faculty of Dentistry, \\ Misr International University, Cairo, Egypt
}

Mohamed Mohamed Elashiry,,2, Shehab Eldin Saber ${ }^{2,3} \quad$ Salma Hasan Elashry²,4

\begin{abstract}
Address for correspondence Mohamed Mohamed Elashiry, BDS, MSc, Department of Periodontics, Dental College of Georgia, Augusta University, 1120 15th Street, CB 2717, Augusta, GA 30912, United States (e-mail: moelashiry@augusta.edu).
\end{abstract}

Eur J Dent 2020;14:70-76

\begin{abstract}
Keywords

- canal centering

- canal volumetric change

- microcomputed tomography

- single file

- transportation
\end{abstract}

Objectives To evaluate the shaping ability of four different single-file systems using micro-computed tomography (micro-CT).

Materials and Methods Eighty mesiobuccal and mesiolingual canals of permanent mandibular molars were randomly assigned to four groups according to the file used; WaveOne Gold, RECIPROC Blue, HyFlex EDM, and One Shape $(n=20)$. The samples were scanned using micro- $\mathrm{CT}$ for the preinstrumentation record; then the canals were instrumented and scanned for the postinstrumentation records.

Statistical Analysis The data were then analyzed statistically using one-way analysis of variance (ANOVA) with the level of significance set at $\alpha=0.05$.

Results The results of canal centering ratio and canal transportation showed that no significant difference was found among the four file groups at the middle and the coronal levels. However, a significant difference was found at the apical level $(p<0.05)$, where WaveOne Gold showed the best centering ratio and the least amount of canal transportation. The change in the canal volume was significant at the coronal level $(p<0.05)$, whereas the change in the canal volume was higher for the HyFlex EDM group than the other groups. No significant difference was found between the other groups at the apical level, middle level, or in the total percentage of canal volume.

Conclusion WaveOne Gold produced a more centralized canal preparation with a lesser amount of transportation at the apical level. HyFlex EDM showed the highest canal volumetric change at the coronal level. The interim design of the endodontic files has a high impact on the behavior of the file inside the root canal.

\section{Introduction}

The shaping of the root canals system is an essential and critical step in the process of endodontic treatment. The importance to mechanically debride and shape the root canals is not only to remove the vital and necrotic tissue and disrupt the bacterial biofilm but also to provide a space for the antimicrobial irrigation solutions and medicaments to perform their action on the bacteria and to disinfect the root canal. ${ }^{1,2}$

The revolution in the manufacturing of root canal instruments leads to a great variety of these endodontic instruments. Although these variations are valuable in providing different alternatives that can cope with the variations in the root canal system, however, the performance of these instruments inside each canal is not always predictable. ${ }^{3-5}$

The invention of the NiTi rotary instrumentation was advantageous in minimizing the procedural errors and time of treatment. ${ }^{6}$ A new technique for instrumentation was introduced by Yared, where a single file was used in a reciprocating motion rather than rotation, overcoming the large sequence of files used in a rotation motion. ${ }^{7}$ Although some studies described the higher performance of the reciprocating 
motion, other studies showed that the rotary files produced more centralized preparations and less transportation. ${ }^{8,9}$ These controversies have been reported to a large extent, and this dictates that extensive studies should be carried to compare the performance of these motions and file designs using the most accurate and reliable tool for analysis. ${ }^{10}$

Microcomputed tomography (micro-CT) is considered a useful and noninvasive technique that permits the proper visualization of different parts of the canals with higher resolution and accurate details, thus providing a reliable method to evaluate the behavior of different endodontic instruments in different parts of the root canal system. ${ }^{11}$ Micro-CT is the recommended and the ideal radiographic scanning technique for in vitro studies. ${ }^{12}$

The objective of the present study was to evaluate the effect of four different single-file systems, namely WaveOne Gold, RECIPROC Blue, HyFlex EDM, and One Shape, on canal centering, canal transportation, and change in the canal volume using micro-CT.

\section{Materials and Methods}

A total of 80 mesiobuccal and mesiolingual canals of extracted human permanent mandibular molars were used for the study after calculating the total sample size using the $G^{*}$ Power 3.1.9.4 software (Franz Faul, Universität Kiel, Germany) with power of $0.84 .^{13}$ This study was approved by the Research Ethics Committee of Ain Shams University (Cairo, Egypt) under approval no. FDASU-RECID 021607. The soft tissue and organic debris were removed by placing the samples in $5.25 \% \mathrm{NaOCl}$ for 10 minutes and then placing in normal saline until the time of the experiment. After the access cavity was prepared for all the samples, a size 10 $\mathrm{K}$-file was introduced into the canals to check for the apical patency and maintain a glide path. The length of each canal was determined by passing a size $10 \mathrm{~K}$-file slightly beyond the apex then adjusting it to be $0.5 \mathrm{~mm}$ from the apex. Only a size $10 \mathrm{~K}$-file was used before canal preparation with the single-file systems. According to the method described by Pruett, mesial canals with an intermediate radius of curvature $(\mathrm{r}>4$ and $\mathrm{r} \leq 8 \mathrm{~mm}$ ) and angle of curvature ranging between $25^{\circ}$ and $35^{\circ}$ were selected for this study. ${ }^{14}$ The canals were randomly allocated to the four groups according to the file system used ( $\mathrm{n}=20$ ) using the GraphPad QuickCalcs random number calculator (https://www.graphpad.com/quickcalcs/ randomize2). Then the average canal radius and curvature of each group were checked to confirm that the groups are comparable statistically with no significant difference between the canal curvatures or diameters before canal preparation.

For the WaveOne Gold group (Dentsply Maillefer; Ballaigues, Switzerland), the size 25 primary file with a $7 \%$ taper was used according to the manufacturer instructions; the file was introduced into the canal with in-and-out picking motion until reaching the full working length (WL). In the RECIPROC Blue group (VDW, Munich, Germany), the R25 with a size of 25 and $8 \%$ taper was used in the same manner as WaveOne gold files; these two files were used in a reciprocating motion. For the Hyflex
EDM group (COLTENE/Whaledent AG, Switzerland), the size 25 primary file with taper $8 \%$ was used according to the manufacturer instructions using a speed of $400 \mathrm{rpm}$ and maximum torque of $2.5 \mathrm{Ncm}$. In the One Shape group (Micro-Mega, Besançon, France), size 25 file with taper 6\% was used in a rotation motion at the same speed of the Hyflex EDM files, but the torque was set at $2.0 \mathrm{Ncm}$. An endodontic motor with both rotation and reciprocation motion was used for the four groups (X-SMART PLUS; Dentsply Maillefer, Ballaigues, Switzerland). To ensure that the same length of the file's working part used was introduced into the canals, the samples used have an average tooth length of $19 \pm 0.5 \mathrm{~mm}$.

A 30-G long needle was used for irrigation. The irrigating needle was inserted before preparation to remove any debris that may interfere with the files and preventing them from reaching the full WL. A total of $5 \mathrm{~mL}$ of $0.9 \%$ saline (sodium chloride $[\mathrm{NaCl}]$ ) was carried into the canal by picking motion. Where the insertion of the file inside the root canal was followed by insertion of the irrigating needle to the canal level prepared, a $1 \mathrm{~mL}$ of irrigation was inserted with picking motion to prevent any blockage until the file reached the full $\mathrm{WL}$, then a complete flush of the canal was done $^{15} ; 17 \%$ ethylenediaminetetraacetic acid (EDTA) gel (Glyde; Dentsply Maillefer, Ballaigues, Switzerland) was used as a lubricant. Each file was used for only four canals and then discarded.

\section{Micro computed Tomography Analysis}

The teeth were scanned before and after preparation using high-resolution desktop micro-CT scanner SkyScan (SkyScan 1174; SkyScan, Bruker, Belgium), then were placed in a specific mold that holds the teeth in a reproducible position during the whole time of scanning. The microfocus X-ray tube was set at $50 \mathrm{kV}$ of acceleration voltage, $800 \mu \mathrm{A}$ of beam current. Scanning was performed at $32.17 \mu \mathrm{m}$ resolution, and a $0.5 \mathrm{~mm}$ aluminum filter was placed for filtration of the X-ray beam to remove unwanted low energy beams. The rotation step angle was $0.50^{\circ}$, with approximately 3,800 seconds of exposure time. Reconstruction of the images was done using NRecon software (SkyScan 1174), the ring artifact correction was set at 10 , and beam hardening correction was set at 15 .

\section{Evaluation of Centering Ratio and Canal Transportation}

Canal centering ratio and canal transportation were analyzed using the CTAn V.1.18.8.0 (SkyScan 1174) software according to technique developed by Gambill et al, which measures the distance from the edge of the canal to the periphery of the root (mesial and distal) on pre- and postinstrumentation images of micro CT ( - Fig. 1). The following formula was implemented for canal centering: $\left(\mathrm{X}-\mathrm{X}^{\prime}\right) /\left(\mathrm{Y}^{\prime} \mathrm{Y}^{\prime}\right)$. According to this formula, a result of " 1 " will indicate a perfect centering ability; results higher than " 1 " will indicate more mesial movement and results lesser than " 1 " will indicate more distal movement. ${ }^{16}$ This formula (X-X') - (Y-Y') was used for canal transportation where results higher or lesser than 0 indicates canal transportation. ${ }^{16}$ 


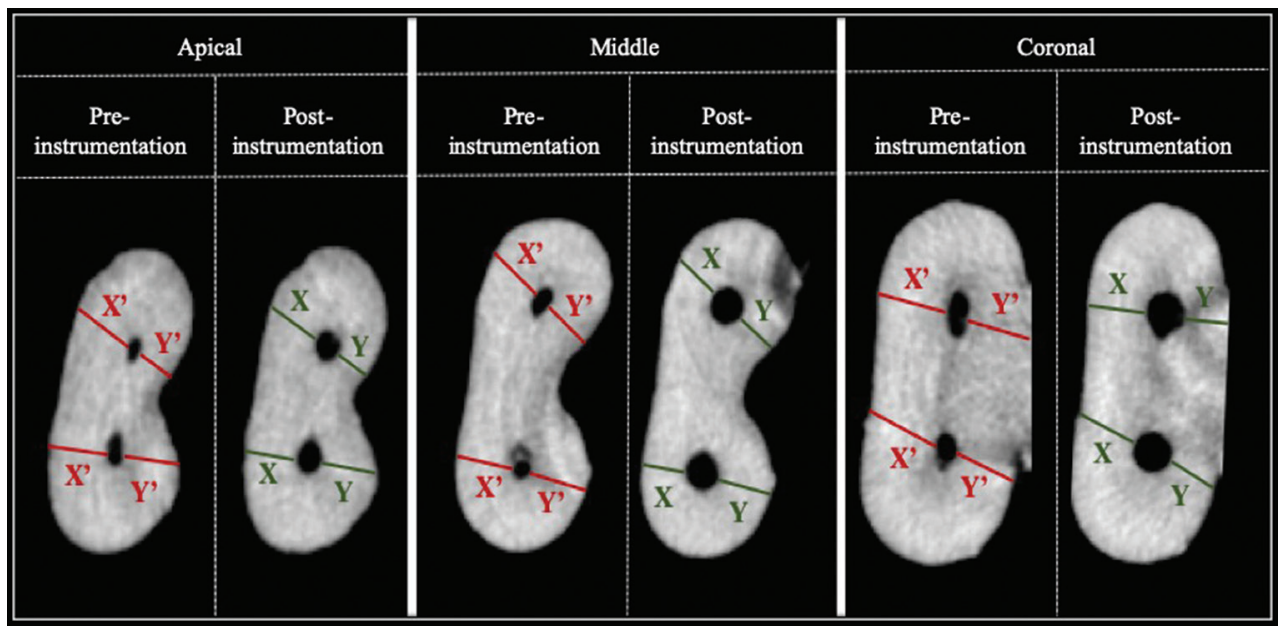

Fig. 1 Cross-sectional reconstructed images showing the measurements taken on the preinstrumentation and postinstrumentation images at the apical, middle, and coronal levels. On the figure: $X$ denotes the shortest distance from the mesial aspect of the root to the periphery of the prepared canal. $X^{\prime}$ denotes the shortest distance from the mesial aspect of the root to the periphery of the unprepared canal. The same for $Y$ and $Y^{\prime}$.

The canals were divided into three parts: apical, middle, and coronal $(3,5$, and $7 \mathrm{~mm}$ from the apex, respectively). The pre- and postinstrumentation records were done at the same number of scanned slices from the apex.

\section{Measurements of Canal Volume Percentage Change}

The pre and post instrumentation images were superimposed over each other using the three-dimensional (3D) registration (-Fig. 2) of the DataViewer software V. 1.5.6.3 (SkyScan 1174), then the superimposed images were saved. The volumetric changes at three canal levels were then calculated using the CTAn software V. 1.18.8 (SkyScan 1174) (-Fig. 3).

\section{Statistical Analysis}

The data passed the normality test and were statistically analyzed using one-way analysis of variance (ANOVA). Post hoc pairwise comparisons were conducted using the Tukey test (GraphPad Prism version 7.00 for Windows, GraphPad Software, La Jolla, California, United States). The statistical significance level was set at $p<0.05$.

\section{Results}

\section{Canal Centering}

The results are shown in - Table 1. No significant difference was found in the centering ability of the four groups at the coronal level $(p=0.083)$ or the middle level of the canals $(p=0.131)$. At the apical level, the difference was significant $(p<0.05)$, where the WaveOne Gold group showed the best centering ratio among the other groups.

\section{Canal Transportation}

There was no significant difference in canal transportation between the four groups at the coronal level $(p=0.567)$ or the middle level ( $p=0.246$ ). However, WaveOne Gold showed the least canal transportation at the apical level $(p<0.05)$. The results are shown in $\boldsymbol{- T a b l e} \mathbf{2}$.

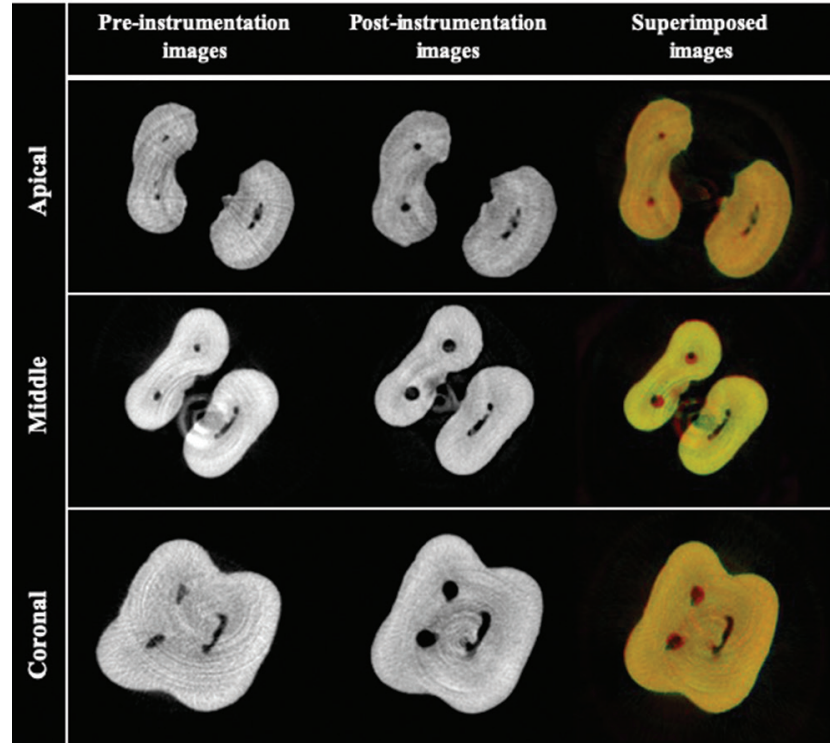

Fig. 2 Cross-sectional reconstructed images showing the preinstrumentation, postinstrumentation, and the superimposed images at the three different canal levels. The red color in the superimposed images indicate the difference in the canal parameters after instrumentation.

\section{Change in Canal Volume}

The results are shown in - Table 3 . The results showed that there was a significant difference in canal volumetric changes between the four groups at the coronal level $(p<0.05)$, where the HyFlex EDM group showed the highest canal volumetric changes. No significant difference was found among the four groups in the total percentage of canal volume change $(p=0.616)$, in the percentage of canal volume change at the apical level ( $p=0.655)$, or the middle level $(p=0.49)$.

No significant difference in canal volumetric changes at the different canal levels for the same type of file was found for WaveOne Gold group ( $p=0.144$ ) and the RECIPROC Blue group $(p=0.058)$; however, there was a significant difference 


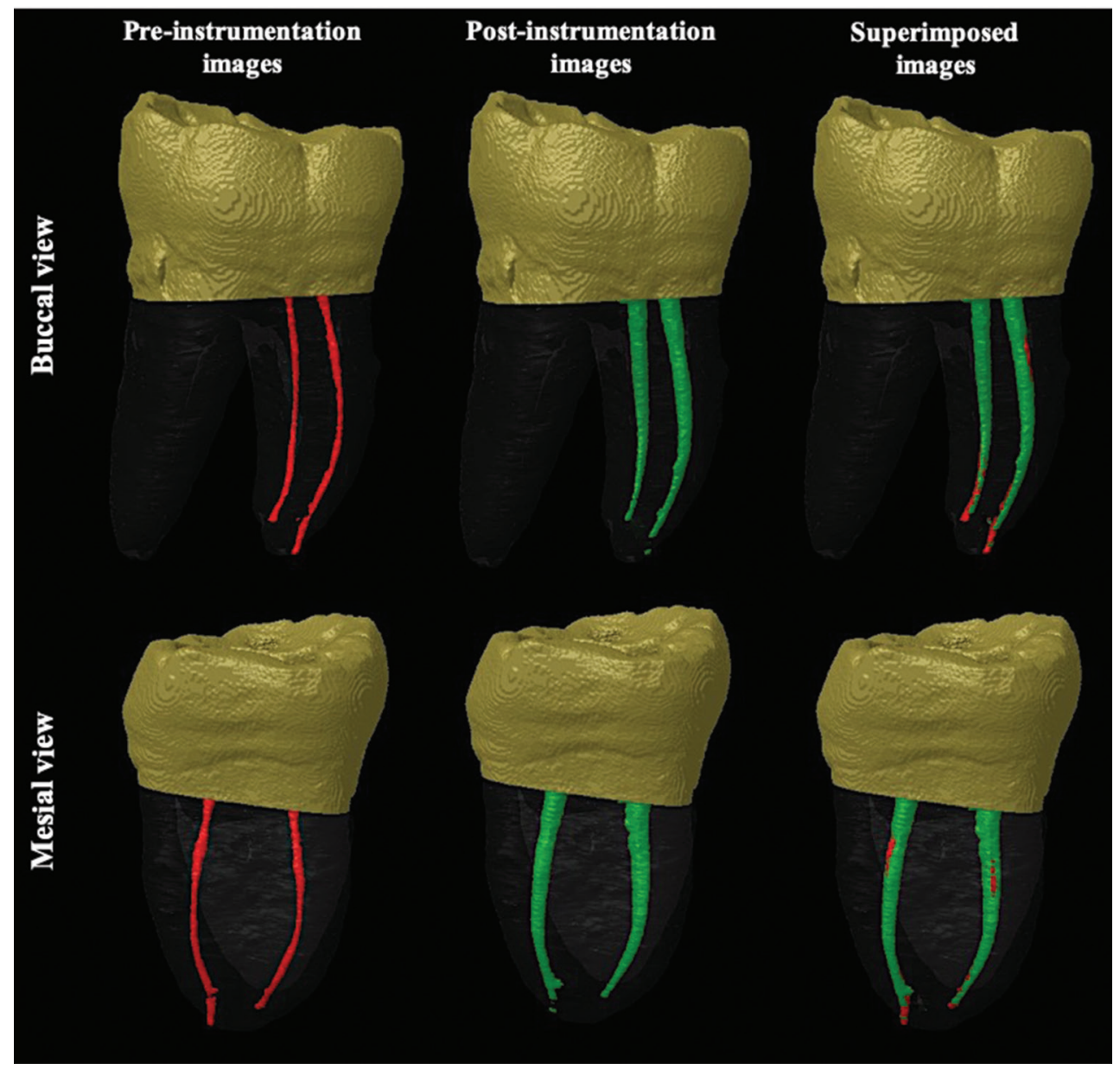

Fig. 3 Representative 3D reconstructed images showing the total canal volume; before instrumentation in red color, after instrumentation in green color, and the superimposed image of the pre- and postinstrumentation micro-CT images in two different views: buccal and mesial. 3D, three-dimensional; CT, computed tomography.

Table 1 The mean and standard deviation of canal centering ratio for the four groups in different levels of the root canal: apical, middle, and coronal

\begin{tabular}{|l|l|l|l|}
\hline \multirow{2}{*}{ Group } & \multicolumn{3}{|c|}{ Canal level } \\
\cline { 2 - 4 } & $\begin{array}{l}\text { Apical } \\
\text { Mean } \pm \text { SD }\end{array}$ & $\begin{array}{l}\text { Middle } \\
\text { Mean } \pm \text { SD }\end{array}$ & $\begin{array}{l}\text { Coronal } \\
\text { Mean } \pm \text { SD }\end{array}$ \\
\hline WaveOne Gold & $1.458 \pm 0.344$ & $0.813 \pm 0.223$ & $0.891 \pm 0.349$ \\
\hline RECIPROC Blue & $2.049 \pm 0.479$ & $0.919 \pm 0.401$ & $0.94 \pm 0.491$ \\
\hline HyFlex EDM & $1.64 \pm 0.436$ & $0.958 \pm 0.408$ & $0.928 \pm 0.309$ \\
\hline One Shape & $2.226 \pm 0.376$ & $0.726 \pm 0.278$ & $0.838 \pm 0.343$ \\
\hline
\end{tabular}

Abbreviation: SD, standard deviation.

in the HyFlex EDM group and the One Shape group $(P<0.05)$, where the canal volumetric change was highest at the coronal level in both groups.

\section{Discussion}

One of the critical criteria and prerequisites for optimal instrumentation of the root canals is the preservation of the original canal outline, curvature, and centering. The ability of the endodontic files to respect the anatomy of the canals is vital to prevent the procedural errors that may occur in different parts of the canals, such as transportation in the apical third, strip perforations in the middle third or weakening of the coronal part by cutting more cervical dentin. ${ }^{17}$

The mesial canals of the mandibular molars usually represent a challenge in the endodontic treatment owing to their curvature, and anatomical variations and the proper selection of the endodontic files that will respect these anatomical variations is fundamental. ${ }^{18}$ The canals were selected with an intermediate radius of curvature $(r>4$ and $r \leq 8 \mathrm{~mm})$ and angle of curvature ranging between $25^{\circ}$ and $35^{\circ}$ for this study to represent the curvature angle and radius found in the majority of the mesial canals of mandibular molars as indicated by previous studies. ${ }^{19-21}$ 
Table 2 The mean and standard deviation of canal transportation for the four groups in different levels of the canal: apical, middle, and coronal

\begin{tabular}{|c|c|c|c|}
\hline \multirow[t]{2}{*}{ Group } & \multicolumn{3}{|c|}{ Canal level } \\
\hline & $\begin{array}{l}\text { Apical } \\
\text { Mean } \pm S D \\
\mathrm{~mm}\end{array}$ & $\begin{array}{l}\text { Middle } \\
\text { Mean } \pm \text { SD } \\
\text { mm }\end{array}$ & $\begin{array}{l}\text { Coronal } \\
\text { Mean } \pm S D \\
\mathrm{~mm}\end{array}$ \\
\hline WaveOne Gold & $0.035 \pm 0.033$ & $-0.025 \pm 0.011$ & $-0.028 \pm 0.026$ \\
\hline RECIPROC Blue & $0.068 \pm 0.58$ & $-0.021 \pm 0.019$ & $-0.02 \pm 0.019$ \\
\hline HyFlex EDM & $0.052 \pm 0.05$ & $-0.019 \pm 0.017$ & $-0.021 \pm 0.017$ \\
\hline One Shape & $0.086 \pm 0.065$ & $-0.033 \pm 0.023$ & $-0.03 \pm 0.026$ \\
\hline
\end{tabular}

Abbreviation: SD, standard deviation.

Table 3 The mean and standard deviation of canal percentage volumetric change after preparation with the examined files at different levels of the canal

\begin{tabular}{|l|l|l|l|l|}
\hline \multirow{2}{*}{ Group } & \multicolumn{3}{|c|}{ Canal level } & $\begin{array}{l}\text { Total volume change } \\
\text { Mean } \pm \text { SD } \\
\%\end{array}$ \\
\cline { 2 - 5 } & $\begin{array}{l}\text { Apical } \\
\text { Mean } \pm \text { SD } \\
\%\end{array}$ & $\begin{array}{l}\text { Middle } \\
\text { Mean } \pm \text { SD } \\
\%\end{array}$ & $\begin{array}{l}\text { Coronal } \\
\text { Mean } \pm \text { SD } \\
\%\end{array}$ & $25.3 \pm 11.1$ \\
\hline WaveOne Gold & $18.81 \pm 16.12$ & $14.71 \pm 9.51$ & $25.59 \pm 11.97$ & $23.39 \pm 12.66$ \\
\hline RECIPROC Blue & $19.27 \pm 10.87$ & $16.09 \pm 6.82$ & $37.58 \pm 11.39$ & $25.47 \pm 6.35$ \\
\hline HyFlex EDM & $20.42 \pm 4.66$ & $19.15 \pm 5.4$ & $33.37 \pm 1.8$ & $20.72 \pm 8.27$ \\
\hline One Shape & $15.05 \pm 11.72$ & $13.94 \pm 12.19$ & & \\
\hline
\end{tabular}

Abbreviation: SD, standard deviation.

This study aimed to evaluate if the difference in the design of the endodontic files and the motion kinematics may have an implication on canal centering, canal transportation, and the change in canal volume after preparation.

Microcomputed tomography has been used in this study as it represents an innovative technique for 3D imaging. It produces scanned images with very high resolution and fine details, overcoming many of the drawbacks of the other imaging techniques. Micro-CT is considered a highly acceptable, standardized, and reliable method to be used in the evaluation of many endodontic studies. ${ }^{12,22,23}$

To study the performance of the instruments examined through the whole canal length, the analysis of three different canal levels-apical, middle, and coronal levels, represented by $3 \mathrm{~mm}, 5 \mathrm{~mm}$, and $7 \mathrm{~mm}$ from the apex, respectively, was performed. ${ }^{21,24,25}$

The results of this study showed that at the middle and the coronal levels, there was no significant difference between the four groups in canal centering ratio or the amount of canal transportation. However, at the apical level, WaveOne Gold files showed the best centering ratio and the least amount of canal transportation. WaveOne Gold files are manufactured from the Gold wire by using advanced metallurgy and proprietary thermal treatment. ${ }^{26}$ The cross-section of WaveOne Gold is a parallelogram with two $85^{\circ}$ cutting edges that contact the canal wall, alternating with off-center cross-section, only one cutting edge is in contact with the canal wall, it is utilized in a reciprocating motion and has a regressive taper, ${ }^{27}$ the special heat treatment the file received and these characteristic design features improved the file performance inside the root canals. ${ }^{28}$ RECIPROC Blue is another file used in reciprocating motion, the files are produced with Nickel-Titanium that goes through an innovative heat treatment, modifying its molecular structure to give the files an enhanced characteristics, ${ }^{29}$ the cross-section of RECIPROC Blue files is an S-shaped with regressive taper. ${ }^{30}$ Although WaveOne Gold and RECIPROC blue are both used in reciprocating motion, however, the difference between them in the centering ratio and the amount of canal transportation suggest that the file characteristics such as the surface treatment, cross-sectional design or the taper have more influence on the file performance rather than the motion kinematics. This finding is consistent with previous studies that showed that the instrument's features had significant influences on the mechanical properties of the NiTi instruments. ${ }^{27}$ Although previous study reported the superiority of WaveOne Gold over RECIPROC Blue in canal centering and transportation, ${ }^{26}$ another study showed that no difference was found in canal transportation between HyFlex EDM and WaveOne Gold; these discrepancies in the results may be attributed to the study design where they used simulated resin canals which is not the case in this study where natural canals were used and analyzed with the highly accurate micro-CT. ${ }^{31}$ It has been reported that WaveOne Gold showed a better centering ability than One Shape which is evident in this study. ${ }^{32}$ Previous studies showed similar performance for WaveOne Gold..$^{25,33,34}$ It was found that all the four groups showed a centering ratio more than one at the apical level indicating the tendency of all the instruments used to prepare more of the outer surface of the canal curvature rather than the inner surface. ${ }^{17}$ 
The results of the change in canal volume showed that the four file groups behaved similarly at the apical level, middle level, and for the total volumetric change; however, at the coronal level, the HyFlex EDM group produced the highest percentage change in canal volume. HyFlex EDM group and One Shape group showed a difference in canal volumetric changes between different levels of the canal when prepared with the same type of file. Studies on canal volumetric changes using these file types have not been extensively studied before, and hence it was difficult to correlate our current results with previous data. HyFlex EDM has a cross-section that is variable along its entire length. The file has an almost triangular cross-section design at the coronal part, followed by a trapezoidal cross-section design and ends with a quadratic cross-section design at the apical third. ${ }^{35}$ There are always four points of contact for the file with the canal walls. The file used in a rotation motion, has a continuous taper and made of a controlled memory alloy using electric discharge machining technology, which enhanced its cutting efficacy. ${ }^{36}$ Although WaveOne gold and RECIPROC Blue received a thermal treatment that improved their cutting efficiencies, the difference in the taper and hence in the amount of the metal core may influence the difference in the canal volumetric change, where it is continuous for HyFlex EDM and regressive for WaveOne Gold and RECIPROC Blue. ${ }^{37}$ One shape file is designed to have three different cross-section designs along the length of the files starting with three symmetrical cutting edges at the apical part, it ends with two S-shaped cutting edges in the coronal part. ${ }^{38}$ Although HyFlex EDM and One Shape both have a continuous taper, however, the lack of surface treatment in One Shape may explain the higher canal volume change in the HyFlex EDM group at the coronal level. ${ }^{36}$

The difference in canal volumetric change between the different levels of the canals prepared with HyFlex EDM group or One Shape group may be correlated to the transition from different designs in the cutting edges and the continuous increase in metal core of these two groups. ${ }^{39}$

As the differences exist among the four single-file systems in the centering ratio and canal transportation at the apical level and in the volumetric canal change at the coronal level, the null hypothesis has to be rejected. It is important to evaluate the behavioral nature of different files to ensure that the proper selection of the files that will respect the original canal anatomical features is applied and the subsequent achievement of long-term successful endodontic treatment.

\section{Conclusion}

Within the limitations of this study, it was concluded that WaveOne Gold showed the best performance regarding canal centering ratio and the amount of canal transportation at the apical level, all the files performed similarly at the middle and the coronal levels of the canal.

Preparation with HyFlex EDM produced a greater change in canal volume than the other groups at the coronal level. No difference in canal volumetric change between the tested files was found at the other two levels of the canal.
The performance of the endodontic files during canal instrumentation is dependent mainly on the interim cross-sectional design, the taper, and the thermal or surface treatment.

\section{Note}

This work should be attributed to Dental College of Georgia, Augusta University, Georgia, United States.

\section{Authors' Contributions}

All authors have contributed significantly and are in agreement with the manuscript.

\section{Conflict of Interest}

None declared.

\section{Acknowledgments}

This project was funded by the Cultural Affairs and Mission Sector, Egyptian Ministry of Higher Education, Egypt.

\section{References}

1 Schilder H. Cleaning and shaping the root canal. Dent Clin North Am 1974;18(2):269-296

2 Hülsmann M, Peters OA, Dummer PM. Mechanical preparation of root canals: shaping goals, techniques and means. Endod Topics 2005; 10:30-76

3 Mamede-Neto I, Borges AH, Guedes OA, de Oliveira D, Pedro FLM, Estrela C. Root canal transportation and centering ability of nickel-titanium rotary instruments in mandibular premolars assessed using cone-beam computed tomography. Open Dent J 2017;11:71-78

4 Agarwal RS, Agarwal J, Jain P, Chandra A. Comparative analysis of canal centering ability of different single file systems using cone beam computed tomography-an in-vitro study. J Clin Diagn Res 2015;9(5):ZC06-ZC10

5 Gundappa M, Bansal R, Khoriya S, Mohan R. Root canal centering ability of rotary cutting nickel titanium instruments: a meta-analysis. J Conserv Dent 2014;17(6):504-509

6 Del Fabbro M, Afrashtehfar KI, Corbella S, El-Kabbaney A, Perondi I, Taschieri S. In vivo and in vitro effectiveness of rotary nickel-titanium vs manual stainless steel instruments for root canal therapy: systematic review and meta-analysis. J Evid Based Dent Pract 2018;18(1):59-69

7 Yared G. Canal preparation using only one Ni-Ti rotary instrument: preliminary observations. Int Endod J 2008;41(4):339-344

8 Hamid HR, Gluskin AH, Peters OA, Peters CI. Rotary versus reciprocation root canal preparation: initial clinical quality assessment in a novice clinician cohort. J Endod 2018;44(8):1257-1262

9 Sousa-Neto MD, Silva-Sousa YC, Mazzi-Chaves JF, et al. Root canal preparation using micro-computed tomography analysis: a literature review. Braz Oral Res 2018;32(suppl 1):e66

10 Pedrinha VF, Brandão JMDS, Pessoa OF, Rodrigues PA. Influence of file motion on shaping, apical debris extrusion and dentinal defects: a critical review. Open Dent J 2018;12:189-201

11 Dowker SE, Davis GR, Elliott JC. X-ray microtomography: nondestructive three-dimensional imaging for in vitro endodontic studies. Oral Surg Oral Med Oral Pathol Oral Radiol Endod 1997;83(4):510-516

12 Marciano MA,Duarte MAH,Ordinola-ZapataR, DelCarpio-Per ochena A, Cavenago BC, Villas-Bôas MH, et al. Applications of micro-computed tomography in endodontic research. Current Microscopy Contributions to Advances in Science and Technology (A. Méndez-Vilas, Ed.) 2012:782-788 
13 Faul F, Erdfelder E, Lang AG, Buchner A. G*Power 3: a flexible statistical power analysis program for the social, behavioral, and biomedical sciences. Behav Res Methods 2007;39(2):175-191

14 Pruett JP, Clement DJ, Carnes DL Jr. Cyclic fatigue testing of nickel-titanium endodontic instruments. J Endod 1997;23(2): 77-85

15 Dioguardi M, Gioia GD, Illuzzi G, Laneve E, Cocco A, Troiano G. Endodontic irrigants: different methods to improve efficacy and related problems. Eur J Dent 2018;12(3):459-466

16 Gambill JM, Alder M, del Rio CE. Comparison of nickel-titanium and stainless steel hand-file instrumentation using computed tomography. J Endod 1996;22(7):369-375

17 Young GR, Parashos P, Messer HH. The principles of techniques for cleaning root canals. Aust Dent J 2007;52(1, Suppl):S52-S63

18 Peters OA. Current challenges and concepts in the preparation of root canal systems: a review. J Endod 2004;30(8):559-567

19 Schäfer E, Diez C, Hoppe W, Tepel J. Roentgenographic investigation of frequency and degree of canal curvatures in human permanent teeth. J Endod 2002;28(3):211-216

20 Estrela C, Bueno MR, Sousa-Neto MD, Pécora JD. Method for determination of root curvature radius using cone-beam computed tomography images. Braz Dent J 2008;19(2):114-118

21 Wu XC, Zhu YQ. Geometric analysis of root canals prepared by single twisted file in three different operation modes. Eur J Dent 2014;8(4):515-520

22 Swain MV, Xue J. State of the art of Micro-CT applications in dental research. Int J Oral Sci 2009;1(4):177-188

23 Grande NM, Plotino G, Gambarini G, et al. Present and future in the use of micro-CT scanner 3D analysis for the study of dental and root canal morphology. Ann Ist Super Sanita 2012;48(1):26-34

24 Shivashankar MB, Niranjan NT, Jayasheel A, Kenchanagoudra MG. Computed tomography evaluation of canal transportation and volumetric changes in root canal dentin of curved canals using Mtwo, ProTaper and ProTaper Next Rotary System-an in-vitro study. J Clin Diagn Res 2016;10(11):ZC10-ZC14

25 Vallabhaneni S, Fatima K, Kumar TH. Cone-beam computed tomography assessment of root canal transportation using WaveOne Gold and Neoniti single-file systems. J Conserv Dent 2017;20(6):434-438

26 Keskin C, Demiral M, Sarıyılmaz E. Comparison of the shaping ability of novel thermally treated reciprocating instruments. Restor Dent Endod 2018;43(2):e15
27 Alcalde MP, Duarte MAH, Bramante CM, et al. Cyclic fatigue and torsional strength of three different thermally treated reciprocating nickel-titanium instruments. Clin Oral Investig 2018;22(4):1865-1871

28 Singh S, Mirdha N, Shilpa PH, Tiwari RVC, Abdul MSM, Sainudeen S. Shaping ability of 2Shape and WaveOne Gold Files using cone-beam computed tomography. J Int Soc Prev Community Dent 2019;9(3):245-249

29 Yared G. Reciproc Blue: the new generation of reciprocation. G Ital Endod 2017;31:96-101

30 De-Deus G, Silva EJ, Vieira VT, et al. Blue thermomechanical treatment optimizes fatigue resistance and flexibility of the Reciproc files. J Endod 2017;43(3):462-466

31 Özyürek T, Yılmaz K, Uslu G. Shaping ability of Reciproc, WaveOne GOLD, and HyFlex EDM single-file systems in simulated S-shaped canals. J Endod 2017;43(5):805-809

32 van der Vyver PJ, Paleker F, Vorster M, de Wet FA. Root canal shaping using Nickel Titanium, M-Wire, and Gold Wire: a micro-computed tomographic comparative study of One Shape, ProTaper Next, and WaveOne Gold instruments in maxillary first molars. J Endod 2019;45(1):62-67

33 Al-Dhbaan A, Al-Omari M, Mathew S, Baseer M. Shaping ability of ProTaper gold and WaveOne gold nickel-titanium rotary file in different canal configurations. Saudi Endod 2018;8:202-207

34 Matus D, Betancourt P. Mechanical root canal preparation using the WaveOne Gold ${ }^{\circledR}$ system-case series. Biomed Res 2018;29:2686

35 Iacono F, Pirani C, Generali L, et al. Structural analysis of HyFlex EDM instruments. Int Endod J 2017;50(3):303-313

36 Gündoğar M, Özyürek T. Cyclic fatigue resistance of OneShape, HyFlex EDM, WaveOne Gold, and Reciproc Blue Nickel-Titanium instruments. J Endod 2017;43(7):1192-1196

37 Mittal S, Gupta S, Sharma D, Sharma A, Mittal K. Effect of taper and metallurgy on cleaning efficacy of endodontic files in primary teeth: an in-vitro study. J Paediatr Dent 2015;3:75-81

38 Reddy PJ, Kumar VS, Aravind K, et al. Canal shaping with one shape file and twisted files: a comparative study. J Clin Diagn Res 2014;8(12):ZF01-ZF03

39 Guillén RE, Nabeshima CK, Caballero-Flores H, et al. Evaluation of the WaveOne Gold and One Shape New Generation in reducing Enterococcus faecalis from root canal. Braz Dent J 2018;29(3):249-253 